\title{
Inhalt
}

Einleitung: Ererben und Erwerben . . . . . . . . . 7 (Manfred Nössig)

\section{Dispute und Rezensionen}

Zwei Debatten . . . . . . . . . . . . . . 49

Etwas über Maßstäbe . . . . . . . . . . . . . . . . 49

(Manfred Nössig, Michael Hamburger, Hendrik Arnst, Ursula Püschel, Klaus Pfützner, Christoph Funke)

Viermal "Hamlet" und viele Fragen offen . . . . . . . .

(Liane Pfelling, Martin Linzer, Gert Jurgons, Gisela Begrich/ Werner Freese, Anselm Schlösser, Michael Hamburger, Manfred Nössig)

Kritiken und Aufsätze . . . . . . . . . . . . . . . . . . . 99 (Manfred Nössig)

Goethe: Faust I - Halle . . . . . . . . . . . . . . . 99

Schiller : Due Räuber - Volksbühne Berlin . . . . . . . . 109

Goethe: Urfaust - Annaberg, Eisenach, Greifswald . . . . . . 115

Schiller : Wallensten-Trilogie - Leipzig . . . . . . . . . 122

Klassıker am Stadtthẹater (Goethe: Egmont - Görlitz/Zittau, Schiller : Dıe Räuber-Frankfurt/Oder, Shakespeare : Maßfür Maß -

Bautzen, Shakespeare: Otbello - Stendal) . . . . . . . . . 128

Shakespeare: Hamlet - Leipzig . . . . . . . . . . . 136

Shakespeare: Hamlet - Weimar . . . . . . . . . 142

Shakespeare: Otbello - Stendal . . . . . . . . . . . 144

Shakespeare: Otbello - Weimar . . . . . . . . . . . 147

lbsen: Jobn Gabriel Borkimann - Dresden . . . . . . . . . . 150

Ibsen : Die Wildente - Volksbühne Berlin . . . . . . . . . 153

Strindberg: Erık XIV. - Maxim Gorki Theater Berlin . . . 158 
Gorki: Nacbtasyl - Halle . . . . . . . . . . . . . 162

Gorki: Barbaren - Maxim Gorki Theater Berlin . . . . . . . . 167

Über den Umgang mit Brecht-Stücken (Leben des Galilei - Landes-

bühnen Sachsen, Der gute Menscb von Sezuan - Karl-Marx-Stadt,

Der Kaukasiscbe Kreidekreis - Wittenberg) . . . . . . . . 173

Brecht: Der gute Menscb von Sequan - Volksbühne Berlin . . . . 182

Brecht: Herr Puntila und sein Knecbt Matti - Dresden, Gera . . . 184

Brecht: Turandot oder Der Kongreß der Weißwäscber - Berliner En-

semble . . . . . . . . . . . . . . . . . 190

Brecht: Die Mutter - Berliner Ensemble . . . . . . . . . 196

Anhang

Abkürzungen . . . . . . . . . . . . 201

Anmerkungen . . . . . . . . . . . . 202

Werke des Erbes im Repertoire - Eine Statistik . . . . . . 211

(Manfred Nössig)

Chronik und Bibliographie zur Erbe-Debatte 1970-1974 . . . . 235

(Manfred Starke)

Personen- und Werkregister . . . . . . . . . . . . . 256 